\title{
Emergency Department Visits and Deaths from Cardiovascular Diseases at a Referral Center for Cardiology During the COVID-19 Pandemic
}

Luis Sérgio Carvalho Luciano, ${ }^{1,2}$ Luiz Eduardo Koenig São Thiago, ${ }^{1,2}{ }^{\circledR}$ Isabela de Carlos Back, ${ }^{3}$ Leandro Waldrich, ${ }^{1,2}$ Luiza Di Bernardi de São Thiago, ${ }^{4}$ Amabile Rodrigues Alves, ${ }^{4}{ }^{\circledR}$ Beatriz Campos Comelli, ${ }^{4}{ }^{\circledR}$ Mariane Janning Santos, ${ }^{4}$ Luiz Carlos Giuliano ${ }^{1,2}{ }^{\circledR}$

Instituto de Cardiologia de Santa Catarina, 'São José, SC - Brazil

Hospital SOS Cárdio, Florianópolis, ${ }^{2}$ SC - Brazil

Universidade Federal de Santa Catarina, ${ }^{3}$ Florianópolis, SC - Brazil

Universidade do Sul de Santa Catarina, ${ }^{4}$ Florianópolis, SC - Brazil

\section{Abstract}

Background: The COVID-19 pandemic has imposed measures of social distancing and, during this time, there has been an elevation in cardiovascular mortality rates and a decrease in the number of emergency visits.

Objectives: To assess and compare in-hospital mortality for cardiovascular diseases and emergency department visits during the COVID-19 pandemic and the same period in 2019.

Methods: Retrospective, single-center study that evaluated emergency visits and in-hospital deaths between March 16, 2020 and June 16, 2020, when the steepest fall in the number of emergency admissions for COVID-19 was registered. These data were compared with the emergency visits and in-hospital deaths between March 16 and June 16, 2019. We analyzed the total number of deaths, and cardiovascular deaths. The level of significance was set at $\mathrm{p}<0.05$.

Results: There was a 35\% decrease in the number of emergency visits and an increase in the ratio of the number of deaths to the number of emergency visits in 2020. The increase in the ratio of the number of all-cause deaths to the number of emergency visits was $45.6 \%$ and the increase in the ratio of the number of cardiovascular deaths to the number of emergency visits was $62.1 \%$. None of the patients who died in the study period in 2020 tested positive for COVID-19.

Conclusion: In-hospital mortality for cardiovascular diseases increased proportionally to the number of emergency visits during the COVID-19-imposed social distancing compared with the same period in 2019.

Keywords: Cardiovascular Diseases; Emergency Service, Hospitalar; COVID-19; Betacoronavirus/complications; Hospitalization; Visitors to Patients; Hospitals, Packaged; Pandemics.

\section{Introduction}

In December 2019, in the city of Wuhan, capital of Hubei Province, in China, the first cases of a new disease that would reach global proportions and become devastating in many aspects were identified..$^{1-3}$ The world has watched the spread of this disease caused by the new coronavirus (COVID-19) from Asia to Europe and then to the Americas in less than three months. On March 11, 2020, the World Health Organization (WHO) ${ }^{1}$ announced the COVID-19 outbreak a pandemic.

In addition to its rapid transmission, even by presymptomatic and asymptomatic infected individuals, the SARS-CoV-2 (severe acute respiratory syndrome coronavirus 2) has significantly higher mortality as compared with other coronaviruses associated with 
respiratory diseases and may progress to pneumonia and acute respiratory distress syndrome (ARDS), notably in elderly patients and in those with comorbidities. ${ }^{4}$ Global mortality rate has varied from 1 to $5 \%$, with more than 600,000 deaths registered on 20 July, 2020. The number of confirmed cases surpasses 14 million. ${ }^{5}$

The effects of COVID-19 go beyond the respiratory tract, affecting the cardiovascular and the nervous system also. ${ }^{4,-9}$ The psychological and economic impacts of social distancing policies have been a challenge to health system and financial managers worldwide. . $^{10,11}$

Patients have avoided medical care due to concerns about viral exposure in the hospitals. New York city and other cities severely hit by the COVID outbreak have reported an elevation in the number of deaths from acute myocardial infarction (AMI) and other cardiovascular diseases, and a drastic reduction in the number of emergency admissions for these conditions. ${ }^{12,13}$

Thus, our objective was to assess in-hospital mortality from cardiovascular diseases in relation to the number of emergency visits for these conditions during the SARS$\mathrm{CoV}-2$ pandemic, and to compare these data with those of the same period in 2019 in a cardiology referral center in Santa Catarina, in southern Brazil.

\section{Methods}

This was a retrospective, single-center study of the analysis of emergency records and in-hospital deaths at the participating institution, which is a referral center for treatment of highly complex cases in cardiology in the state, and sees patients through the unified health system (SUS) only. Approximately 10,900 visits are made to the emergency department annually, mostly for cardiovascular diseases, and 272 patients underwent primary angioplasty in 2019 at this hospital.

Emergency visits and in-hospital deaths registered between March 16, 2020 and June 16, 2020 (period when there was a drastic reduction in emergency visits because of the pandemic-induced social distancing) were included in the analysis. These data were compared with the emergency visits and in-hospital deaths registered between March 16, 2019 and June 16, 2019.

All-cause mortality and cardiovascular mortality during these periods were analyzed. Cardiovascular mortality was defined according to the International Classification of Diseases, tenth revision (ICD-10), as available, and by review of medical charts.
Cardiovascular causes of death were determined using the circulatory system diseases listed in the ICD-10 code range I00-I99. After analysis of the incidence of overall and cardiovascular deaths in proportion to the number of emergency visits, we analyzed the incidence of deaths by cardiovascular cause, notably AMI (ICD-10 I21), heart failure (HF) (ICD-10 I50), stroke (ICD-10 I60-I64) and subcategories. Exclusion criteria were lack of data on emergency admissions in the hospital statistical report, and restrict access to the electronic medical records for analysis of the medical history of patients who had died.

The number of all-cause and cardiovascular deaths and the number of emergency visits were analyzed weekly during the periods of study (total of 13 weeks/ year), so that curves of the course of these variables, and curves of the relationship between deaths and emergency visits over time were constructed.

The following variables were compared between the two periods of study (2019 vs. 2020): number of all-cause deaths, number of cardiovascular deaths, demographic profile (age and sex) of participants who died, number of emergency visits, ratio of the number of all-cause deaths to the number of emergency visits, and ratio of the number of cardiovascular deaths to the number of emergency visits. We also analyzed the number of beds in intensive care unit (ICU) between 2019 and 2020 and the possible increase in the number of patients referred to the institution in this period.

The study was approved by the ethics committee of the institution (approval number 34042720.5.1001.0113). All study procedures were conducted according to the Helsinki declaration (2013 version). Written informed consent was waived due to the retrospective nature of the study.

\section{Statistical Analysis}

Data were stored in an Excel spreadsheet and then exported to IBM SPSS Statistics ${ }^{\circledR}$ 18.0. Categorical variables were presented as frequencies (absolute and relative) and continuous variables as mean and standard deviation. In the bivariate analysis, Pearson chi-square test was used for categorical variables, and the independent t-test was used for continuous variables, depending on data normality, which was tested by the Kolmogorov-Smirnov test. Values of $p<0.05$ were considered statistically significant.

Analysis of temporal trends of the number of emergency visits per week was conducted by simple linear regression, with construction of an estimated 
model using the formula $\mathrm{Y}=\mathrm{b} 0+\mathrm{b} 1 \mathrm{X}$, where $\mathrm{Y}=$ standard coefficient, $\mathrm{b} 0=$ mean coefficient for the period, $\mathrm{b} 1=$ mean annual increment and $X=$ year; $a \mathrm{p}<0.05$ was considered statistically significant. All assumptions for conducting the simple linear regression were previously checked.

\section{Results}

There was an increase in the number of beds in ICU from 2019 to 2020; new beds were placed in ICU on April 04, 2020, indicating an elevation in the number of beds for severely ill patients during nearly two-thirds of the study period (Figure 1). No expansion in the health service coverage or in coverage area was observed from 2019 to 2020.

Mean age of patients who died in 2019 and 2020 was 74.1 years (standard deviation, SD 11.2 years) and 70.0 years (SD 11.1years), respectively, with no statistical difference $(p=0.067)$. Analysis of the number of deaths by age range $(<65$ years, $\geq 65$ and $<75$ years, $\geq 75$ and $<85$ years and $\geq 85$ years) in 2019 and 2020 showed no statistical difference in the incidence of deaths by age group between the two years.
Most deaths occurred in male patients $-51.9 \%$ of deaths in 2019 and 58.8\% of deaths in 2020 ( $\mathrm{p}=0.473$ ) - and due to cardiovascular causes (Figure 2). This is in agreement with the mortality profile of patients seen in the institution. No statistical difference was seen in the proportional incidence of cardiovascular deaths between 2019 and 2020 ( $p=0.326$ ). The medical history of all patients who died in this two-year period could be accessed through the electronic medical records.

The total number of emergency visits decreased from 2019 to 2020, leading to an elevation in the ratio of the number of deaths to the number of emergency visits in 2020. The ratio of all-cause deaths to emergency visits and the ratio of cardiovascular deaths to emergency visits increased by $45.6 \%$ and $62.1 \%$, respectively in 2020 (Table 1).

Figures 3-5 show the weekly course of the number of emergency visits, ratio of all-cause deaths to emergency visits, and the ratio of cardiovascular deaths to emergency visits in 2019 and 2020. The relation of in-hospital deaths to emergency visits was expressed as percentage.

Analysis of temporal trends revealed a stable pattern in emergency visits per week in 2019 ( $p=0.981)$ and a

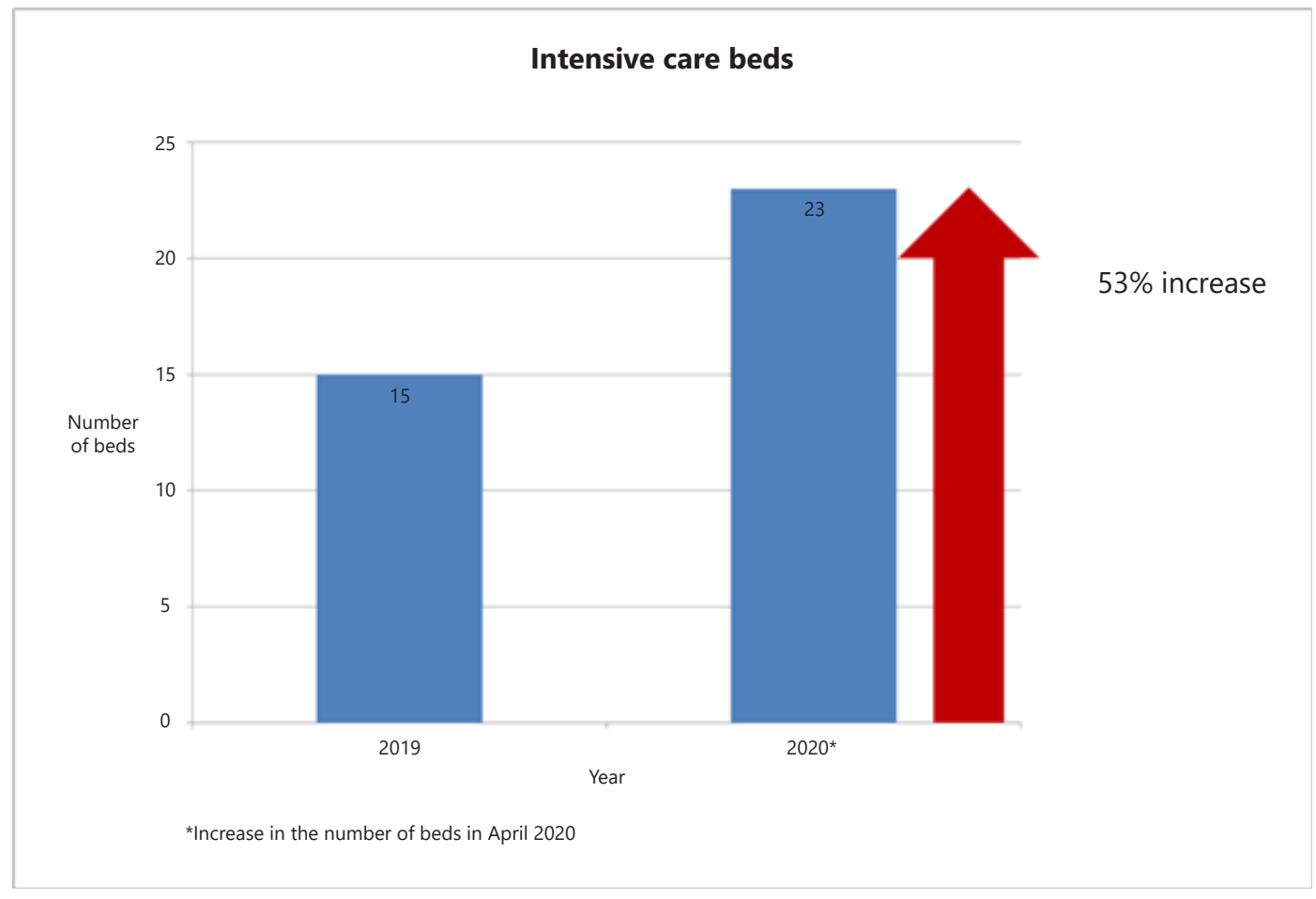

Figure 1 - Number of ICU beds in 2019 and 2020. 
Table 1 - Total deaths, cardiovascular deaths, emergency visits, ratio of all-cause deaths to emergency visits, ratio of cardiovascular deaths to emergency visits and difference in percentages between 2020 and 2019

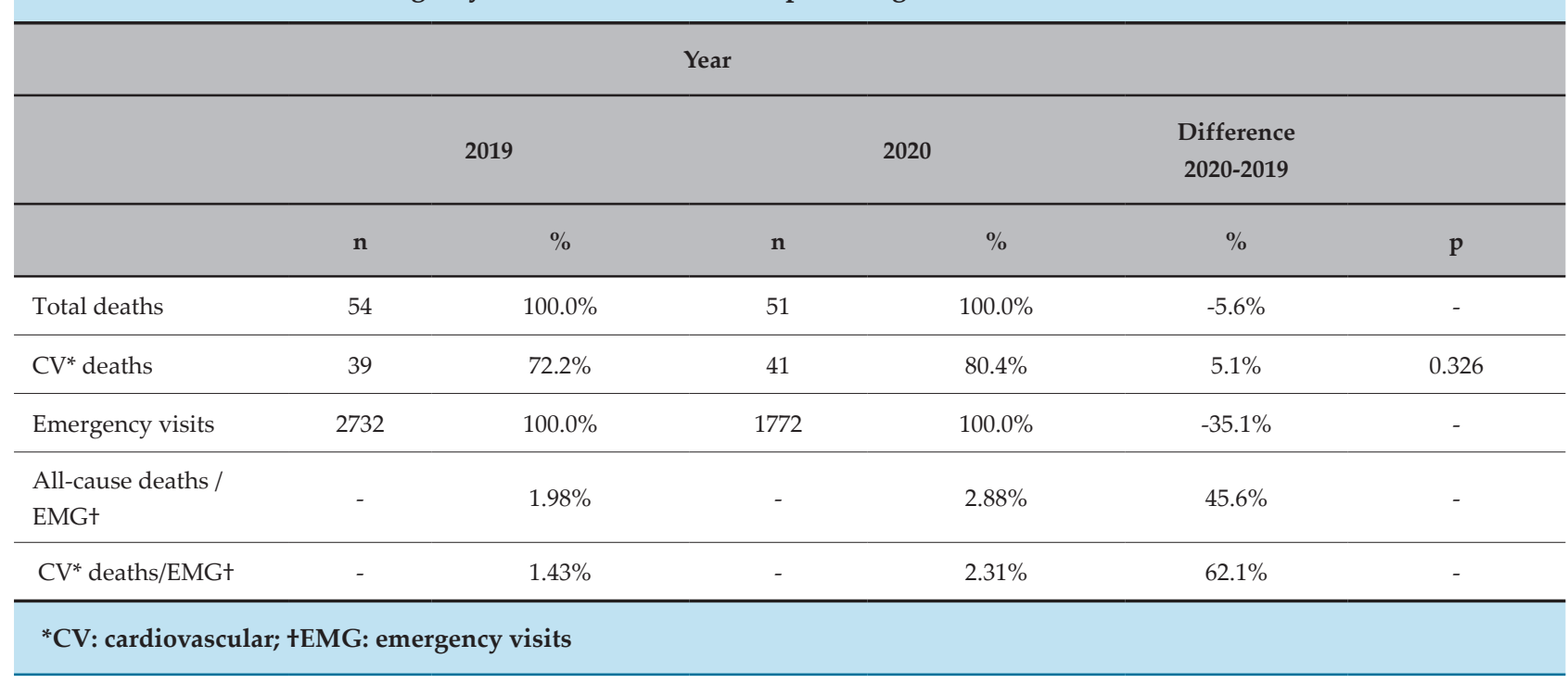

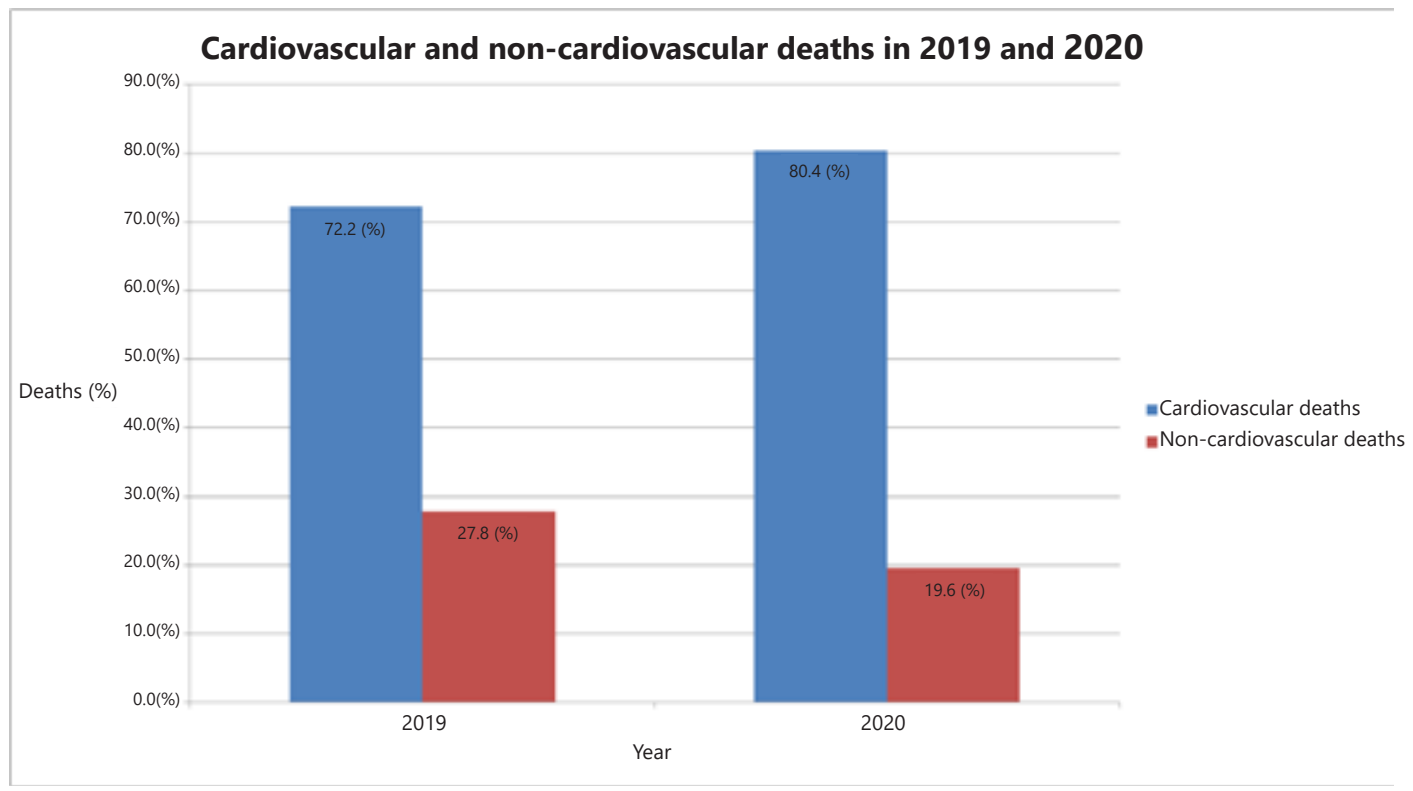

Figure 2 - Proportion of deaths from cardiovascular and non-cardiovascular causes in 2019 and 2020.

tendency of increase by 8.5 emergency visits per week in $2020(\mathrm{p}<0.001)$.

When only cardiovascular deaths were analyzed, we found an increase in the proportion of deaths related to AMI and a decrease in the proportion of deaths related to heart failure in 2020 compared with 2019, with no statistical difference. The number of deaths related to stroke was not significant in our institution in the study period (Table 2).

Other forms of heart diseases, including advanced atrioventricular and left bundle-branch block, aortic aneurysm rupture, aortic dissection, and infectious endocarditis accounted for $28 \%$ of cardiovascular deaths in 2019 and $22 \%$ in 2020. 


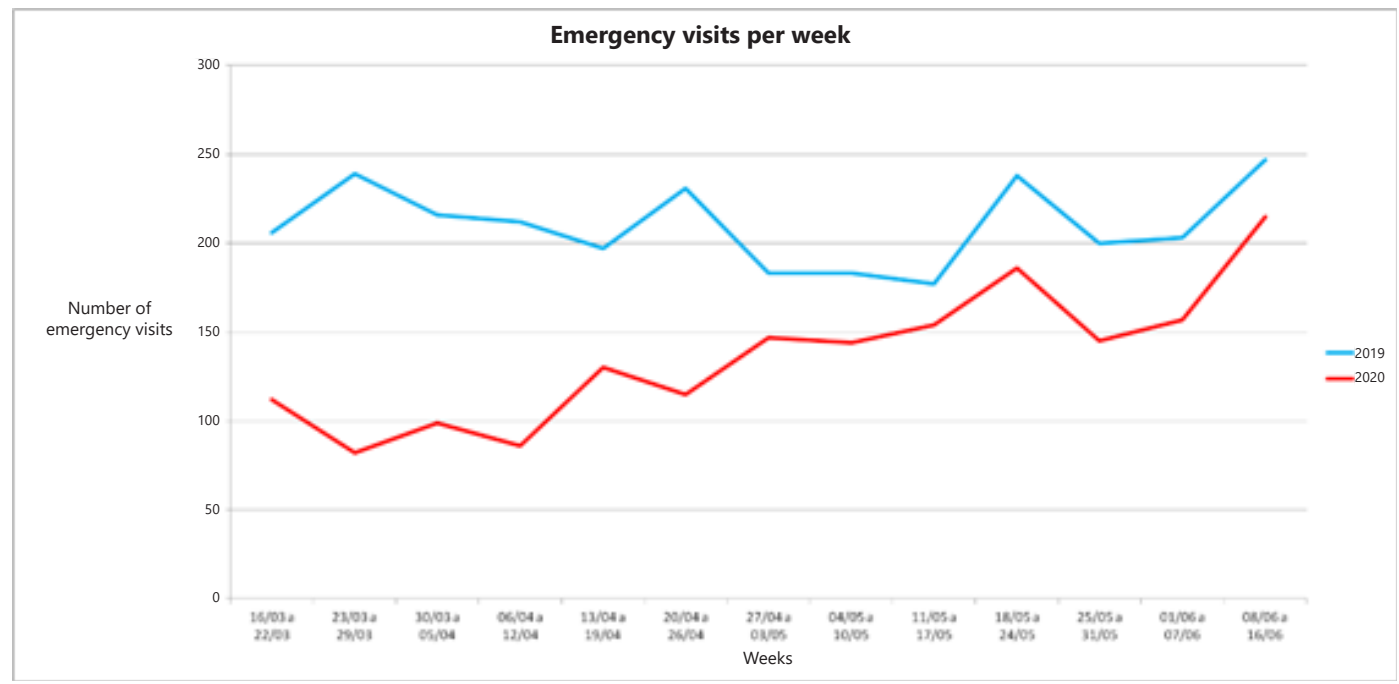

Figure 3 - Graph showing the evolution of the number of emergency visits per week in 2019 and 2020.

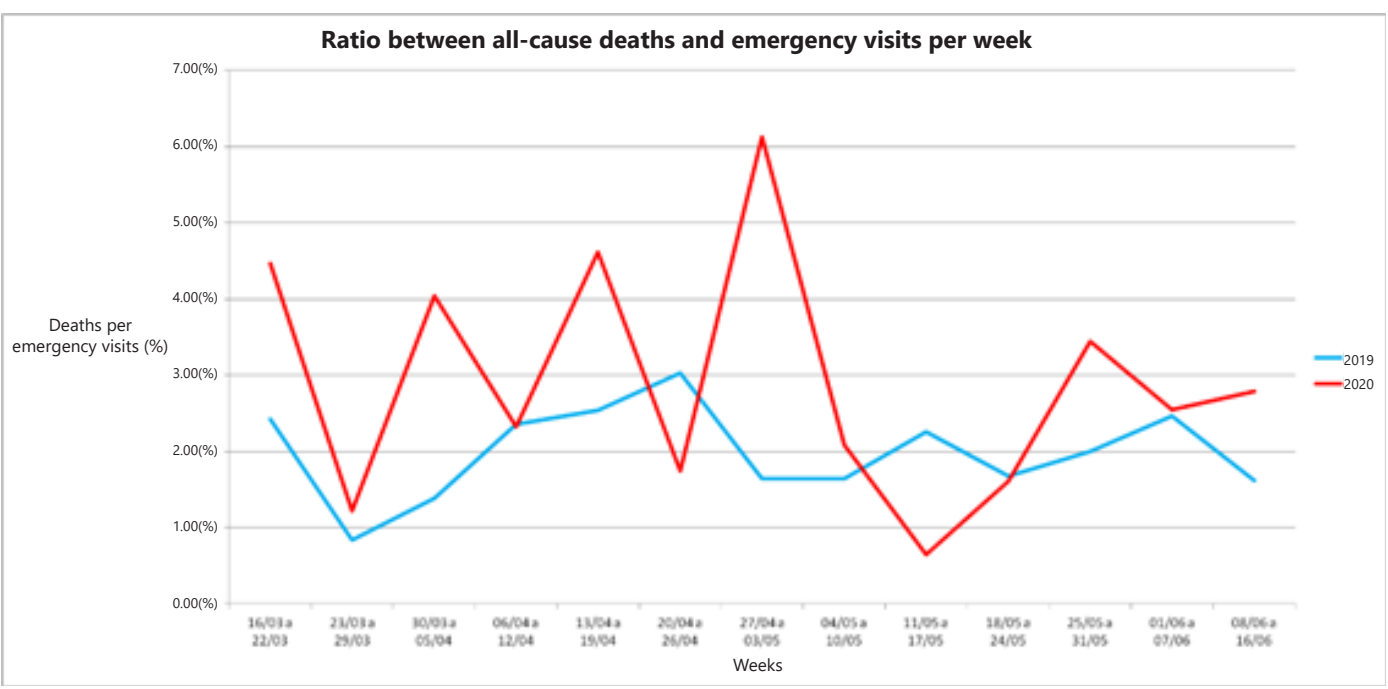

Figure 4 - Graph showing the evolution of the ratio of total deaths / emergency visits per week in 2019 and 2020.

Regarding non-cardiovascular deaths, septicemia was the main cause of deaths in 2019 and 2020. Less frequent causes included upper digestive hemorrhage, acute renal failure, severe bronchospasm, and stage IV cancer. None of the patients who died in 2020 in the study period had a positive COVID-19 test.

\section{Discussion}

On March 17, 2020, the government of Santa Catarina state declared a state of emergency and established social distancing norms because of the COVID-19 pandemic. In the beginning, a strict social distancing was imposed, 


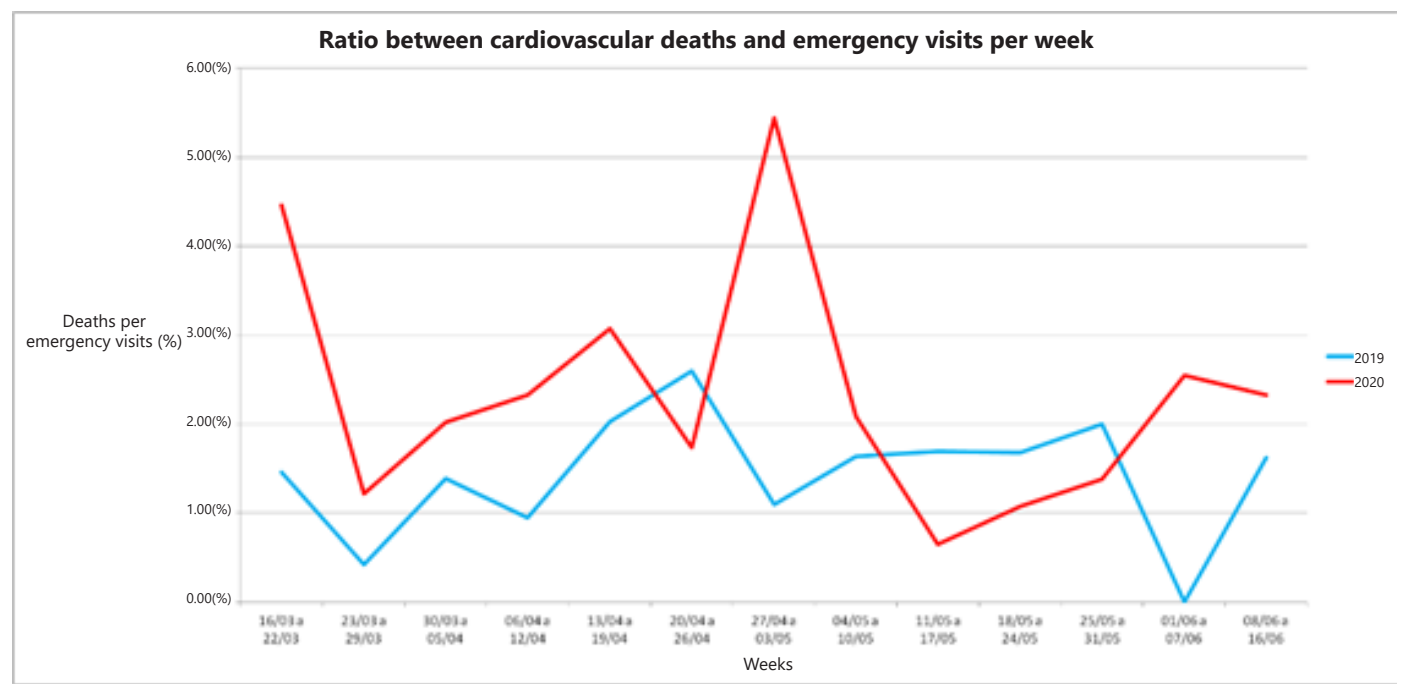

Figure 5 - Graph showing the evolution of the cardiovascular deaths / emergency visits ratio per week in 2019 and 2020.

Table 2 - Distribution of cardiovascular deaths by specific causes in 2019 and 2020

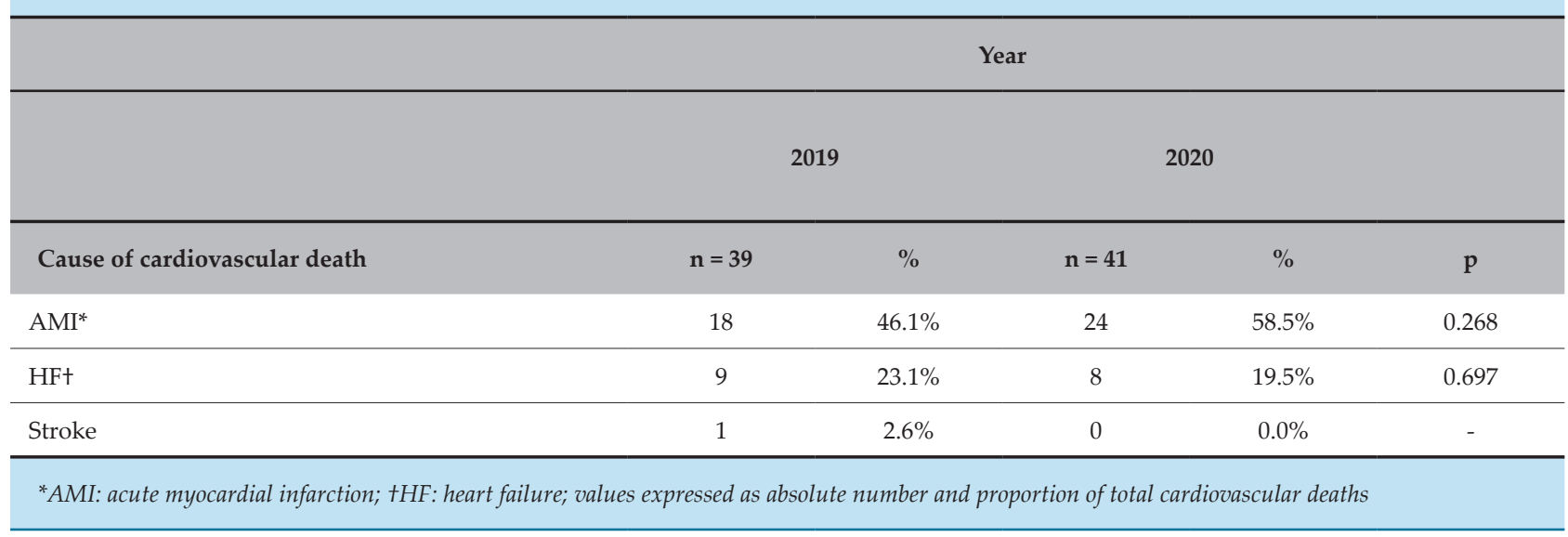

with ban of public transportation, and closing of hotels, gyms, malls, and stores. Government officers warned and pled for people to stay home, which was effective to reduce COVID-19 transmission. The fear of exposure to the new coronavirus was felt by the entire population, especially by the elderly, and may have caused negligence of cardiovascular symptoms . Cardiovascular diseases are the main cause of death worldwide, accounting for 31\% of global deaths. ${ }^{14}$

In the local context, the strategy to reduce coronavirus transmission to improve the infrastructure of health care for patients with ARDS was effective at first, with public policies aimed at assigning resources for providing ICU beds, so that $21.7 \%$ of the intensive care beds would be occupied by patients with suspected or confirmed COVID-19. In our institution, there was a 50\% increase in the number of intensive care beds, and the quality of care of patients without suspected COVID-19 was preserved. Despite this increase in the number of beds, the area covered by the institution did not change in 2020, and hence the increase in the ratio of the number of deaths to the number of emergency visits was not caused by an elevation in the referral of severely ill patients. The absence of deaths from COVID-19 in the analyzed period in 2020 reinforces that there was no significant change in the sample profile. The fact that the study was conducted in a specialized, tertiary- 
care center allowed an analysis of specific effects of social distancing on the cardiovascular system.

During this pandemic, we found that despite the wellknown financial difficulties of SUS and the heterogeneity among the states, the number of ICU beds in Brazil is the third highest in the world, lower only than the United States and Germany. Brazil had advantageous strategies to fight the pandemic and its consequences, especially the time to prepare the health system and knowledge about the disease. However, limitations in the number of diagnostic tests and identification of transmitters have affected our epidemiological viewpoint and we have stuck to social distancing and its consequences. ${ }^{15}$

In light of the need to reduce the likelihood of virus transmission, the demand for diagnosis and treatment of cardiovascular events has decreased. ${ }^{16-18}$ This becomes clear in the comparison of the number of tests and procedures performed in the institution between 2019 and 2020. A total of 1,870 echocardiograms and 1,210 catheterizations were performed in the three-month period (March - June) of analysis in 2019, whereas in the same period of 2020, 870 echocardiograms and 979 catheterizations were performed.

In a context of drastic reduction in the number of emergency visits, the number of deaths per number of emergency visits serves as a parameter for analysis of the incidence of in-hospital deaths. This is of particular importance in an institution where most patients are admitted through the emergency department, including by self-referral, even being a tertiary hospital.

The increase by $62.1 \%$ in the ratio of the number of cardiovascular deaths to the number of emergency visits in 2020 is mainly related to the delay in seeking emergency care due to social distancing policies and reductions in the number of emergency department admissions for less severe illnesses. In addition, interruption of outpatient follow-up has contributed to the increase in cardiovascular mortality. ${ }^{15}$ Similar phenomena have been observed in large urban centers like New York and northern Italy. ${ }^{12,13}$ In an article published in The New York Times in April 2020, Dr. Harlan M. Krumholz calls attention to the sharp fall in the number of hospital admissions for AMI and stroke, and reports a 40-60\% drop in admissions for AMI in the USA according to informal analyses. ${ }^{19}$ The hypothesis is that many symptomatic people are opting to remain at home rather than seek medical care or dying before receiving medical attention. Patients with cardiovascular disorders who seek medical attention only after their condition has worsened are at increased risk of in-hospital death.
An analysis of the Brazilian Society of Cardiology revealed a $30 \%$ increase in the number of cardiovascular deaths occurring at home between March and May 2020 as compared with the same period in the previous year. ${ }^{20}$ While Brazil registered almost 80 thousand deaths from COVID-19 (WHO), ${ }^{21}$ the Brazilian Society of Cardiology estimated that the number of people who died from cardiovascular diseases by July 2020 was almost three times higher, 224 thousand.22 Today the number of deaths from COVID-19 in Brazil exceeds 353 thousand according to the WHO.

The low incidence of stroke-related deaths in the study hospital may be related to the existence of public referral centers for cerebrovascular events in the region.

Considering the increasing number of coronavirus infected, proportional increase in cardiovascular deaths and uncertainties in the duration and consequences of the pandemic, we should be prepared to deal with potential deleterious effects of COVID-19 on the cardiovascular system of patients severely affected by the disease. Late myocardial dysfunction, for example, deserves attention and investigation. ${ }^{23}$

Limitations of the present study include the short period of analysis, which did not represent the whole period of the pandemic and social distancing, and its retrospective singlecenter design, reflecting the reality of a public, tertiary, specialized hospital. Also, we did not evaluate the reasons for emergency visits or the severity of the cases. Besides, it was not possible to analyze the time from symptom onset to hospital presentation, which could explain at least in part the increase in the ratio of cardiovascular deaths to emergency visits in 2020, due to the time-sensitive nature of cardiovascular events. Further studies are needed to elucidate the cardiovascular implications of social distancing in other contexts and regions of Brazil.

\section{Conclusion}

During the COVID-19-related social distancing, inhospital mortality for cardiovascular diseases increased proportionally to the number of emergency visits when compared with the same period in 2019.

\section{Author Contributions}

Conception and design of the research: Luciano LSC, São Thiago LEK. Acquisition of data: Luciano LSC. Analysis and interpretation of the data: Luciano LSC, São Thiago LEK, Back IC. Statistical analysis: Luciano LSC, 
Back IC. Writing of the manuscript: Luciano LSC. Critical revision of the manuscript for intellectual content: Luciano LSC, São Thiago LEK, Back IC, Waldrich L, São Thiago LB, Alves AR, Comelli BC, Santos MJ, Giuliano LC.

\section{Potential Conflict of Interest}

No potential conflict of interest relevant to this article was reported.

\section{Sources of Funding}

There were no external funding sources for this study.

\section{Study Association}

This study is not associated with any thesis or dissertation work.

\section{Ethics approval and consent to participate}

This study was approved by the Ethics Committee of the Instituto de Cardiologia de Santa Catarina under the protocol number 34042720.5.1001.0113. All the procedures in this study were in accordance with the 1975 Helsinki Declaration, updated in 2013. Written informed consent was waived due to the retrospective nature of the study.

\section{References}

1. Munster VJ, Koopmans M, van Doremalen N, van Riel D, Wit E. A novel coronavirus emerging in China - key questions for impact assessment. N Engl J Med. 2020;382(8):692-4.

2. Guan W, Ni Z, Hu Y, Liang W, Ou C, He J, et al. Clinical characteristics of Coronavirus disease 2019 in China. N Engl J Med. 2020;382(18):1708-20.

3. D'avila A, Vidal Melo MF, Lopes RD. Pandemonium during the pandemic: what is the role of health and science professionals? Arq Bras Cardiol. 2020;114(5):753-4.

4. Costa IBSS, Bittar CS, Rizk SI, Araújo Filho AE, Santos KAQ, Machado TIV, et al. The Heart and COVID-19: what cardiologists need to know. Arq Bras Cardiol. 2020;114(5):805-16.

5. World Health Organization. (WHO) Coronavirus disease (COVID-19) Situation Report - 182 [Internet]. 2020. [acesso em maio 2020]. Disponível em: https://www.who.int/docs/default-source/coronaviruse/situationreports/20200720-covid-19-sitrep-182.pdf?sfvrsn=60aabc5c_2

6. Askin L, Tanrıverdi O, Askin HS. The effect of coronavirus disease 2019 on cardiovascular diseases. Arq Bras Cardiol. 2020;114(5):817-22.

7. Guimarães RB, Falcão B, Costa RA, Lopes MACQ, Botelho RV, Petraco $\mathrm{R}$, et al. Acute coronary syndromes in the current context of the Covid-19 pandemic. Arq Bras Cardiol. 2020;114(6):1067-71.

8. Ferrari F. COVID-19: updated data and its relation to the cardiovascular system. Arq Bras Cardiol. 2020;114(5):823-6.

9. Merkler AE, Parikh NS, Mir S, Gupta A, Kamel H, Lin E, et al. Risk of ischemic stroke in patients with coronavirus disease 2019 (COVID-19) vs Patients with influenza. JAMA Neurol. 2020;77(11):1-7.

10. Cao W, Fang Z, Hou G, Han M, Xu X, Dong J, et al. The psychological impact of the COVID-19 epidemic on college students in China. Psychiatry Res. 2020 May;287:112934.

11. Nicola M, Alsafi Z, Sohrabi C, Kerwan A, Al-Jabir A, Iosifidis C, et al. The socio-economic implications of the coronavirus pandemic (COVID-19): a review. Int J Surg. 2020 Jun;78:185-93.

12. Lai PH, Lancet EA, Weiden MD, Webber MP, Zeig-Owens R, Hall CB, et al. Characteristics associated with out-of-hospital cardiac arrests and resuscitations during the Novel Coronavirus Disease 2019 Pandemic in New York City. JAMA Cardiol. 2020;5(10):1154-63.

13. De Filippo O, D'Ascenzo F, Angelini F, Bocchino PP, Conrotto F, Saglietto A, et al. Reduced rate of hospital admissions for acs during Covid-19 outbreak in Northern Italy. N Engl J Med. 2020;383(1):88-9.

14. World Health Organization. (WHO) Global Health Estimates 2016 Deaths by cause, age, sex, by country and by region, 2000-2016. Geneva: WHO; 2018.

15. Fernandes JL. Covid-19 in Brazil: learning how to walk in the dark without leaving anything behind. Arq Bras Cardiol. 2020;114(6):988-91.

16. Costa IBSS, Rochitte CE, Campos CM, Barberato SH, Oliveira GMM, Lopes MACQ, et al. Cardiovascular imaging and interventional procedures in patients with Novel Coronavirus infection. Arq Bras Cardiol. 2020;115(1):111-26.

17. Falcão BAA, Botelho RV, Sarmento-Leite REG, Costa RA. Update on SBHCI positioning about COVID-19 pandemic. J Transcatheter Interv. 2020 Apr 15;28:eA202004.

18. Mariano GZ, Lemke VG, Paiva MSM, Oliveira GMM. Covid-19 and safety in the cath lab: where we are and where we are headed. Int J Cardiovasc Sci. 2020;33(3):288-94.

19. Krumholz HM. Where have all the heart attacks gone? [Internet]. The New York Times. 2020 [acesso 21 jul 2020]. Disponível em: https:// www.nytimes.com/2020/04/06/well/live/coronavirus-doctors-hospitalsemergency-care-heart-attack-stroke.html

20. Sociedade Brasileira de Cardiologia [Internet]. Mortes por doenças cardiovasculares em domicílio aumentaram mais de $30 \%$ durante a pandemia. 2020 [acesso 21 jul 2020]. Disponível em: https://www.portal. cardiol.br/post/mortes-por-doenças-cardiovasculares-em-domicílioaumentaram-mais-de-30-durante-a-pandemia?lang=en

21. World Health Organization. WHO. Coronavirus Disease (COVID-19) Dashboard - Brazil Situation [Internet]; 2020. [acesso 21 jul 2020]. Disponível em: https://covid19.who.int/region/amro/country/br

22. Sociedade Brasileira de Cardiologia. Cardiômetro [Internet]. [acesso 21 jul 2020]. Disponível em: http://www.cardiometro.com.br/

23. Figueiredo Neto JA, Marcondes-Braga FG, Moura LZ, Figueiredo AMS, Figueiredo VMES, Mourilhe-Rocha R, et al. Coronavirus disease 2019 and the myocardium. Arq Bras Cardiol. 2020;114(6):1051-7. 